\title{
A POSSE CAMPONESA DA TERRA E DA ÁGUA: REVENDO E REVISANDO O NORDESTE DE MINAS GERAIS
}

Margarida Maria Moura ${ }^{1}$

No campesinato, que tem na grota um pedaço de terra onde há morada e roça, a categoria que dá contornos físicos precisos à terra é situ. Ter um situ dá a seu responsável - o pai de família - a condição de situante, palavra sempre complementada por nova explicação: dizem que têm uma situação, indicando aos lavradores uma posição no espaço e no lugar como resultado da moradia, do trabalho e da herança.

A ideia de "livre", mais lembrada como um projeto do que uma concretização de sua condição, opõe-se a de "estar à disposição do fazendeiro", que caracterizava a dependência do agregado, morador da fazenda. Não se trata aqui de consagrar uma oposição perfeita, pois que esta não encontra base empírica de sustentação, uma vez que havia ocasiões em que se estava à disposição do fazendeiro.

Enquanto estar à disposição do fazendeiro era mencionado pelo agregado - um campesinato dependente que tinha casa e roça dentro da fazenda, tipo hoje em extinção - como o que definia sua relação social com o fazendeiro, a autonomia do situante é independência, mas que estava ameaçada e até subjugada, em função dos interesses dominantes em uma nova formação. Sua vida social condensava a lógica de universos contrapostos: a autonomia da terra e do trabalho como realização e aspiração, a subordinação cujas concepções e relações buscavam submetê-lo. Fazendeiros que no passado não detivessem necessariamente a propriedade jurídica das glebas onde exerciam direito exclusivo, faziam-se respeitar pela força mantendo suas fazendas de geração em geração, graças à manipulação judiciária e cartorial. Essa formação é, portanto, de fundamento jurídico ou costumeiro e que o vocabulário local expressa por termos derivados de domínio (área dominada = área controlada de fato, mas não juridicamente) em associação com a ideia de dominação social, mas em contradição com o significado jurídico da palavra (domínio = propriedade legítima). A coexistência do situante

\footnotetext{
${ }^{1}$ Professora do Departamento de Antropologia e do Diversitas - Faculdade de Filosofia, Letras e Ciências Humanas da Universidade de São Paulo
} 
com o domínio podia transmutar-se em convivência no domínio, dando ao primeiro a vivência constante da liberdade anulada ou ameaçada.

Trabalha-se a terra como situante, utilizando o quintal para o plantio de andu e mandioca, a roça para o milho e o feijão, a manga para pasto dos animais e a horta para o plantio de verduras e plantas medicinais. Essas atividades se dão na grota em combinação com a soltura de animais na chapada e também a coleta de plantas medicinais nas épocas em que a grota se encontra mais seca. A grota, terra inclinada que vai até a vereda, onde se localizam os rios mais caudalosos, encontra-se no seu limite superior com a chapada, formando um complexo indissociável do modo de vida.

O situ ou situação acha-se disseminado em outras áreas onde inexiste o complexo grota/chapada, onde existe simplesmente um terreno baixo contínuo que, no entanto, guarda os mesmos aspectos da reprodução social descritos para o groteiro e sua família. Se a situação podia se caracterizar pela independência em relação à fazenda, concentrando-se na reciprocidade com os demais situantes, reciprocidade que se refere à troca de dias de trabalho, às transações preferenciais de terras entre vizinhos e confrontantes, às regras de herança, à insistência com que se alega nada dever, nem ao fazendeiro, nem à coletoria; configurava-se, à primeira vista, como uma confirmação da autonomia camponesa. Mas não era assim que sua existência transcorria. Assediado pela antiga fazenda, sempre propensa a estender seus domínios, tinha essa autonomia periodicamente comprometida. Servia-a no desempenho de tarefas, quando solicitado a troco de homenagens e via sua terra desfazer-se, enquanto forma específica de viver e plantar, transitando entre liberdade e condição, em conjunturas periódicas.

Dois movimentos contrapõem-se na memória e existência do situante: a fazenda, que inexiste dessa forma, hoje, por não ter sido cartorialmente comprovada, mas que existiu no passado; a fazenda que inexistia no passado e passa a se formar hoje com uma feição nova, que pode se designar de agronegócio. Nesse novo contexto, perde sentido o elemento mais valorizado do seu modo de vida, que era o de não ter que pedir morada dentro da fazenda. $\mathrm{O}$ situ, que se extrema com outros pelo princípio separador das águas vertentes - categoria divisória costumeira, já que as águas vertentes têm sua nascente no limite superior da grota onde esta se limita com a chapada -, está sendo, na atualidade, negociado visando a sua venda, mas, em sua maioria, invadido e finalizado. O contexto separador das águas vertentes mostrase de maneira clara no texto de ação divisória que se segue: 
(...) pela chapada extremando a ela pelo lado de cima na beira de um lajedo, em um moirão na cancela, rumo direito à chapada (...) extremo com a (...) e do outro lado do córrego S.J.G., rumo direito com as águas vertentes até extremar com A.R. (...) nas águas do C.N., pelo lado de baixo, extrema com o comprador onde existe uma cerca até a chapada, de ambos os lados do córrego S.J.G., extremando-se pelo lado de baixo em terras de P.P. (...) em um moirão de aroeira que se encontra à margem da estrada, rumo direito até a chapada; na chapada em águas vertentes com terras de M.J.D.C., pelo lado de cima com terras de E.F.L., (...), em uns moirões de cancela, direito até a chapada, dando no imóvel em comum (...). (MOURA, 2018, p. 143).

Nos limites superiores das grotas estão os capões, fontes das águas protegidas por um aglomerado de vegetação densa, onde brotam as que se tornam águas vertentes ao descerem o aclive dos terrenos para abastecerem roças. As águas vertentes podem separar comunidades com vários situs ou separar um situ de outro, porque são várias as corredeiras que descem dos capões. Terra e água estavam indissoluvelmente ligadas de modo a propiciar a continuidade do modo de vida camponês.

Aos sítios o poder da fazenda infligia no máximo litígios divisórios, que só excepcionalmente evoluíam para a tomada da área familiar inteira. Àquele que tinha uma situação cabia a parte do leão nas confrontações decorrentes da imposição de domínio ou de dominium. A situação era alvo de ações de despejo ou ações de reintegração de posse de cunho patronal, que visavam à expulsão dos situantes, para quem em seu lugar se consolidasse a propriedade privada da terra. As invasões dos situs, tendo caráter costumeiro ou judicial, visavam a abranger todo o terreno desses lavradores. Ela define o posseiro como invasor tolerado impondo uma moldura das relações sociais o favorecimento ao suposto proprietário da terra, que descaracteriza a permanência do situante na terra. Era essa violência que se unia, no passado, com a condição: um trato que, renovado continuamente de boca, por meio da cessão do trabalho à fazenda por dois dias semanais, determinava as condições para nela permanecer. Hoje essa violência está concretizando e consumando não apenas a conduta da antiga fazenda já descrita, mas a presença do agronegócio no cimo das chapadas.

É do mesmo repertório de categorias e práticas sociais antigas que a presença do agronegócio gera argumentos para retirar da terra o lavrador que deseja permanecer na terra no comum e na terra parcelar desde seus antepassados. Essas terras, bem como as das fazendas, têm sua origem nas terras devolutas do Estado. A tolerância para com este situante não é mais 
para com invasor tolerado. Ancora-se na erradicação do situ, destacando ângulos da relação que só são claramente explicitados quando estouram demandas. Em ações judiciais de caráter divisório contra situantes, possuidores ou não de formais de partilha, o domínio é insinuado e realizado por meio da invasão, ou seja, sustentada pelo argumento de que áreas que se extremam com esse novo perfil das relações sociais, não têm estatuto autônomo, não são parcelas e, portanto, não exigem tolerância de quem com elas limitam. Isso impede que as famílias de lavradores nela residam separados por cercas ou por algum acidente geográfico natural, como são as próprias águas.

O antigo favor imposto a situantes ficava bem exemplificado com as chamadas cartas de agregação. Em tempos mais recuados era um acerto de boca que desencadeava o domínio dos homens, a imposição de documentos que deviam ser aceitos sob o formato de contratos livres que nada mais eram do que as referidas cartas de agregação. Atualmente, visa-se criar condições para terminar o domínio dos homens por meio de papéis assinados ou violência pura e simples, que preludiam a tomada da terra. A terra é tomada por meio da presença de máquinas no cimo da chapada, que tem como finalidade aplainar o terreno para o futuro plantio de culturas vegetais homogêneas como tais como cafezais e eucaliptais, entre outras formas de grande produção.

A terra removida por tratores é empurrada aleatoriamente aos espaços laterais ao carreador, isto é, as estradas de barro formadas nos cimos das chapadas, sufocam as nascentes de água escondidas nos capões, levando à secagem das águas vertentes, o que anula de uma só tacada a possibilidade da vida camponesa nas grotas, além de anular uma categoria divisória do direito costumeiro local, que é a distinção entre terra de grota e terra de chapada. Acabase também com a coleta de plantas medicinais e com o ciclo anual de levar os animais para a chapada nos períodos em que a chuva é mais rara nas grotas, por serem estas mais úmidas.

À medida que se processa este novo ciclo de mudança, são instaladas cercas divisórias novas que impedem o livre trânsito dos situantes groteiros para as chapadas. Ao mesmo tempo, reedita-se o fenômeno da expulsão pela impossibilidade de o modo de vida prosseguir sem formas básicas para a sua reprodução social. Ou, então, o situante incorpora o habitus da subordinação reciclando suas representações em função dessas novas formas ideológicas da ocupação, que não suprimem as concepções anteriores, mas lhes acrescentam tensões permanentes. É possível por dar a renda a esse novo personagem, o agronegócio, que chega de fora e que propõe à sociedade local o reconhecimento implícito de que agora se tem novo patrão 
ou fazer convite aos que estão prejudicados por este novo contexto de que podem se transformar em empregados do novo empreendimento que vai se instalar, na qualidade, não mais de groteiros, mas de trabalhadores eventuais. São fatos fundamentais para a implantação desse novo estado potencial ou real de dominação por meio de um desencantamento do mundo, como diz Pierre Bourdieu (1966). É com o trabalho direto nas áreas ocupadas por esses novos patrões, complementados por adiantamentos em dinheiro, doações em espécie, ofertas de trabalho para se tornarem cozinheiros dos que já estão trabalhando, motoristas que fazem transportes que relações novas se vão impondo gradualmente, em algumas situações, violentamente, em outras.

No passado, as trocas sociais que se estabeleciam entre o situante e o fazendeiro se fraturavam em duas concepções sobre comportamento político e etiqueta de convivência: submeter-se ao fazendeiro ou resistir à sua conduta. A obediência coagida aparecia invertida à lógica inicial da independência dos modos de vida: atos de solidariedade entre dominantes e dominados davam sentido à vivência da subordinação. Enquanto o velho posseiro relatava que seu "patrão e compadre" não morreria antes que ele tivesse chegado a seu quarto para acompanhá-lo no seu último sopro de vida, uma mulher que trabalhara anos a fio na casa da fazenda relatava com profunda amargura sua condição escravizada por uma patroa despótica. Entretanto, separavam a amizade que efetivamente os unia a seus dominadores (especialmente crianças, doentes, velhos e - no caso acima citado - um velho moribundo) do rancor que nutriam pelos mesmos, pelas coações e privações sofridas. As características dessas relações sociais não eram contratuais; calcavam-se num sistema comportamental próprio, que só se rompeu quando o domínio dos homens se transformou em passaporte para a expulsão definitiva dos homens, para o esvaziamento de um espaço social banhado em regras costumeiras. Não se trata de se romperem relações num lugar para se recriarem em outro, no mesmo contexto rural. A implantação do agronegócio vale-se muitas vezes de relações do passado, mas as extingue num tempo econômico curtíssimo, pois desfaz drasticamente os vínculos com a terra e a água na vida dos situantes.

O assédio da fazenda ao situante tinha certas características assinaladas por Eric Wolf (1966, p. 160, que transitavam da amizade para relação patrão/cliente propriamente dita. "When instrumental friendship reaches maximum point of imbalance, so that one partner is clearly superior to the other in his capacity to grant goods and services, we approach the critical point where friendship give way to the patron-client tie." Era esta passagem que marcava a transição da coexistência para a dependência e, finalmente, da dependência à ameaça e concretização do processo de expulsão. O peso da participação de diferentes famílias de 
situantes na relação de dependência movia-se num sinuoso processo. Para aqueles que não eram diretamente assediados em seus terrenos e em seu trabalho pela "fazenda", a subordinação tinha caráter esporádico: convocados para as grandes obras, como o esgotamento das vargens e grandes desmatamentos, recebiam também alimento durante o dia que trabalhavam. As tarefas eram com sustança. Não surpreende, pois, que também entre eles a categoria homenagem tinha o sentido de pagamento vil, de uma relação que prendia, cativava e segurava o lavrador num elo que se perpetuava no desempenho de novas tarefas assumidas, mantendo elos semelhantes aos da agregação, um fio de conexões com o domínio que consolidava vínculos reais e potencialmente extensíveis a outras esferas da vida social. Não é sem razão que santos patronos do domínio eram alvos de festas para os quais se convidavam os situantes, selando-se no ritual comum um tipo de identidade que só custosamente se obtinha no plano dos desempenhos materiais. O inverso também ocorria, com a participação do domínio nas festas dos santos dos situantes.

Desde a década de 1970, mas enfaticamente nos anos 1990, este quadro se modifica tornando-se o próprio situ objeto de cobiça. Aparece no cenário um testa, que representa interesses muito maiores, suprimindo as relações sociais descritas. O situ passa agora a uma forma de apropriação de terra que só coexiste com a fazenda num contexto de compressão e extermínio. Isso porque o interesse em eliminá-los não provém mais da fazenda, mas da aliança da fazenda com o agronegócio ou, simplesmente, com o agronegócio, que visam ocupar terras para desenvolver grandes projetos. A fazenda, para sobreviver, precisava agir consoante este novo jogo de interesses e, para que isso ocorresse, era preciso: a) invadir situs, fortalecendo-se lado a lado à empresa baseada na renda da terra capitalizada; b) facilitar à própria empresa adventícia apossamentos rápidos de terras devolutas; c) valer-se de sua penetração nas esferas de poder municipal e estadual, que lidam mais diretamente com a questão de terras, no sentido de desacelerar a regularização fundiária de ocupantes. Leia-se, situantes ameaçados por gente de fora.

As categorias pelas quais os situantes explicam tais processos são ofensa e fecho, ambas conotativas de violência. Implicam perda das condições de produção e ferem a etiqueta da convivência sertaneja de forma irremediável. A ofensa significa danificar ou suprimir extremas, que separam áreas apropriadas por donos diferentes; danificar plantações, roças, pomares, bem como o sistema de valores correspondente a tais procedimentos. Fecho significa impedir o ir e vir ao próprio situ, aprisionando o lavrador dentro da área, impedindo seu acesso não somente à terra, à lenha, mas ressecando os terrenos pela falta de água que o ecossistema tradicional 
propiciava nessas áreas, o que, num tempo pretérito, facilitava sobremaneira a presença de famílias camponesas nesses locais.

O despejo é, como a ofensa, um menosprezo ou postergação de preceitos; é também a situação lesada por cercas erguidas de má-fé. O des-pejo é atirar alguém à vergonha; a ofensa é ultraje e injúria, o que unifica essas categorias no mesmo conteúdo semiológico. Na condição de lavradores que veem comprimidos ou suprimidos o seu situ (posseiros) enquanto acesso à terra e acesso à água está em jogo a formação do empreendimento para a especulação imobiliária, para o plantio de café, para o plantio de eucalipto e para o uso da água. Suprime-se também a lógica do favor imposto. Ao impor relações de trabalho a lavradores livres, a antiga fazenda acenava com a "tolerância" de sua autonomia e até com a doação de um terreno a quem paradoxalmente já o controlava antes de a fazenda dominar. Estas permissões e promessas se esboroam, porque não podem conviver com este novo processo social da invasão, nestes casos decorrentes de uma nova lógica econômica de ocupação e produção.

A dissolução dos antigos tratos dá novo tom à convivência. Para que isso ocorra, antes que seja preciso acionar a violência física, colocam-se em prática medidas costumeiras que resultem na manutenção do situante como devedor simbólico do invasor. Arrancados da terra têm que arrancar o que plantaram na terra. Quando expulsos, restava aos antigos situantes a colheita das benfeitorias deixadas. A colheita das benfeitorias é a última instância, o que sobrava para os lavradores que perderam a terra. Comparando a situação do antigo agregado à do situante, nota-se que, entre os primeiros, as ações de indenização por benfeitorias eram propostas junto com reclamações trabalhistas iniciadas por eles sob a forma de ações próprias e, entre os segundos, antes de ações possessórias iniciadas por eventuais fazendeiros, não se procuram soluções amigáveis para a colheita das benfeitorias.

Posses e seus sinônimos costumeiros se ausentavam dos discursos, para que a roça colhida não aparecesse como um direito previsto em lei, no sentido dos códigos vigentes na sociedade nacional, como o Código Civil. Simultaneamente, categorias que denotam contrato são provisoriamente apropriadas para caracterizar as relações sociais. O objetivo em jogo era dispor de condições jurídicas para promover a expulsão por meio do distrato, fórmula existente no Estatuto do Trabalhador Rural, ou seja, a finalização de vínculos entre livres e iguais. A ação judicial possessória ou de despejo, impetrada pelos supostos proprietários da área em litígio, falava sempre a linguagem dos contratos encerrados. 
No entanto, as relações do situante com o domínio não supõem transação monetária, não supõem contratos que se desfazem. Por isso o domínio que invadia o terreno era visto como o malfeitor, no sentido que Max Gluckman (1965, p. 243-244) confere a esse termo. É essa palavra mais próxima que, numa perspectiva comparativa, podia-se considerar sinônima de traição de que os lavradores foram alvo no passado. Essa infração de preceitos do tipo aqui descrito não era concebida e vivida como infração de contrato ou ruptura de contrato, era infração de compromisso, em que o lesado quer de volta aquilo perdeu. Citando Seagle, Gluckman fala do camponês moderno que, roubado em seu rebanho, não quer que o infrator o indenize; ele quer as vacas de volta. No caso do situante, ele queria as terras de volta. Não a terra seca numa proporção até então desconhecida, mas a terra onde corria água em caráter permanente.

A invasão dos situs é fruto mais visível das relações tensas que se estabelecem entre grandes empreendimentos capitalistas e moradores de terras devolutas de grotas e chapada. $\mathrm{O}$ processo social, que se inicia com a formação da fazenda, tem características opostas ao iniciado pela fazenda já consolidada contra seus agregados - e que é o de expulsão/invasão da terra. Trata-se de invadir, para depois expulsar. A formação da fazenda é, sem jogo de palavras, o modo de passagem da própria fazenda para o agronegócio. Se a primeira tem consolidada imemorialmente a propriedade, a segunda quer impor sua existência gradual e violentamente, em área designada terra devoluta e terra camponesa; terra devoluta estadual ou terra devoluta federal. A terra devoluta era do ponto de vista local, terra no comum, no sentido de que possui ocupantes que interagem de acordo com formas costumeiras de apropriação, rompendo as determinações do direito dominante ou o adaptando, sempre que sua atuação se mostrar incoercível.

Sempre que uma fazenda se formava em terra devoluta, sem que o Estado reivindicasse naquele momento controle da mesma, o fazendeiro em potencial e os grileiros que o representavam faziam valer sua própria dominação. Esta se amparava em distintas estratégias: 1) a dominação pessoal, que garantia o controle de terras e homens sem prova documental; 2) o título de propriedade forjado; 3) o documento probatório da propriedade incompleto, como, por exemplo, um antigo formal de partilha da área, invocado como prova de propriedade juridicamente superior à ocupação produtiva da terra que resulta do trabalho do situante e sua família. A escritura do abraço que constituía o ponto final para a compreensão dessas distintas estratégias. Se um proprietário determinado detinha poder político suficiente para impor controle sobre determinada área em comum ou pequenas parcelas ocupadas por famílias de 
situantes sua estratégia será a de dominar tal área, bem mais extensa do que a cartorialmente comprovada. No caso em tela não é só a chapada que é ocupada. Casas e roças trabalhadas e habitadas na grota que eram então transformadas em terras de fazenda hoje são transformadas em terras disponíveis para as empresas.

A escritura do abraço, por um lado, oferecia um patamar mínimo de legalidade ao domínio de vastas fazendas. A fluidez dos modos de apropriação da terra por parte dos situantes garantia sempre que a invasão do seu terreno resultasse em terra de fazenda. A usurpação por parte do fazendeiro dos animais e colheitas dos situantes, como do estabelecimento, pela força de relações de trabalho que subordinavam, transformavam a passagem de uma forma alodial de controle da terra a uma força que se funda na renda-em-produto. Nos dias presentes trata-se de invadir a terra e expulsar os homens, para expandir a renda da terra capitalizada.

A apropriação legal da terra só pode ser feita pela herança e pelo mercado, o confronto do situ com a fazenda é um terceiro caminho que está em jogo: a sua usurpação pela invasão. É aí que a supressão de posses não tem razão social para se constituir a não ser como invasão de posses. Esse processo sobrepõe-se, costumeiramente, à transformação jurídica da posse em pequena propriedade porque a concretização do domínio funciona como ameaça concreta à autonomia da posse, dispensando sua consolidação cartorial, porque, se tentar registrar a terra familiar, irá defrontar-se com a influência de grandes proprietários e grandes grupos na política local e regional que poderão manipular sua requisição de modo a transformá-la em reivindicações impróprias.

O que ocorreu nessas zonas agrárias e que deu um caráter novo irreversível a tais transformações foi que a invasão de posses se tornou o tiro de misericórdia disparado contra agentes sociais mais fracos, com a finalidade de anexar as últimas terras fortes de que se desejava dispor para transformá-las em pastos ou em plantios homogêneos voltados para o mercado. Dito de outra forma, como a fazenda não mais se apoia em relações de favor entre proprietários e confrontantes, pode desrespeitar essa antiga etiqueta de convivência, em prejuízo dos mais desfavorecidos e, por simples violência, apropriar-se do que não lhe pertence.

Se no passado os situantes interagiam com a fazenda através de grandes turmas, que, abrigadas pelo fazendeiro em prédios rústicos, eram postas a trabalhar em grandes destocas e capinas por mixarias (alguns tostões), pequenas doações em alimento e remédios, esse código de relações tornou-se irremediavelmente esgarçado. A integridade dos costumes daqueles que estavam fora do espaço da dominação direta do fazendeiro fundava-se na distância física e 
social das terras, onde havia direto interesse da fazenda. Pedia-se o trabalho, mas não o terreno. Está abalada a viga mestra dessa convivência. A invasão dos situs destrói a coexistência com formas distintas de apropriação da terra; se continuam a existir, é exatamente porque se conflituam abertamente. Trata-se de tomar o conjunto da terra, gerando litígios sobre uma determinada área, como prelúdio de ações mais imperativas e coativas que virão prevalecer. A ameaça ou a prática de cercear as posses e parcelas com arame farpado, impedindo o próprio movimento de ir e vir dos seus habitantes serve para impedir não apenas seu acesso à agua ou a uma manga mais distante resultando em verdadeiro aprisionamento.

Há momentos dos ciclos de vida das famílias de pequenos situantes que os tornam mais vulneráveis a esses acontecimentos: o ato de inúmeros chefes de família se deslocarem para outras áreas do país para trabalho temporário na agricultura, garimpo e barragem. A permanência da família ligada à terra torna o assédio à pequena posse mais eficaz nesse período. É o momento em que o chefe da família está ausente e, portanto, supõe-se que a ousadia possa ir mais longe, já que estão presentes no local somente mãe, filhos e avós. Outro momento do ciclo de vida das famílias em que as invasões ocorrem é o da morte do chefe da família. A inexistência de formais de partilha, a evidência de que não se abriu inventário sobre os bens do falecido pode apressar o processo de invasão. Poderosos confrontantes valem-se dessa informação para começar a ameaçar a família. Essas ameaças são semelhantes àquelas dirigidas no passado a um agregado e sua família, quando se desejava expulsá-los. Mas diferem num ponto crucial: não é a cerca derrubada que caracteriza o cume da violência material, mas a cerca erguida que comprime o lavrador numa verdadeira prisão em seu próprio terreno.

As áreas perdidas por situantes, mediante invasão, envolviam as seguintes práticas: o fazendeiro ofendia a cerca que separava a fazenda do situ, valendo-se do fato de que a documentação inexistia ou era incompleta e alegando que a parte cercada não lhe pertencia. $\mathrm{O}$ pequeno posseiro não passaria de um morador de favor, a quem antepassados do atual fazendeiro haviam destinado a condição de vigia de uma extrema da propriedade. Estava ali colado à fazenda, fisicamente unido por um terreno sem descontinuidades jurídicas ou sociais; servia como trabalhador à fazenda, quando o proprietário o convocava. O que o mantinha ali, sem documentos probatórios, não era senão o favor de um senhor da terra tolerante que lhe permitia a autonomia do terreno. Atualmente não interessa mais anexar terras para dominar os homens - seu objetivo é duplo, porém excludente: ela quer anexar a terra e livrar-se dos homens. Para que essa solução vigore, só é possível a ameaça calcada na violência pura. Se não é iniciada uma ação judicial, a saída da terra se dá num confronto costumeiro: é como se a vida rural da 
família se dissolvesse, junto com o desaparecimento do chefe da família, quando na verdade ela desaparece porque o fazendeiro se baseia na morte do primeiro para fazer desaparecer sua terra também. Não se trata de inaugurar novos tipos de contratos de trabalho, marcando de modo singular as relações sociais, já que o controle social incide sobre a terra, dispensando o controle social que, pela dependência, se exercia sobre os homens. Libertam-se os homens para tornar cativa a terra.

Na chapada, o contínuo movimento de expansão da renda capitalizada permite o acréscimo de áreas cada vez maiores. Além de compra por terceiros simplesmente exerce-se a violência material sendo denominados turbação e esbulho. Por turbação da posse entende-se todo o fato impeditivo do livre uso da posse ou o exercício dela. Todo ato que, em relação à coisa, é executado contra a vontade do possuidor, consiste em turbações ou atos turbativos da posse. Para que se configure a turbação é necessário que o fato ou o ato se mostre injusto, isto é, não apoiado em lei ou não autorizado por mandado judicial. Mesmo que impeçam o exercício da posse, os atos legais são turbativos. Em relação à posse, a turbação mostra-se positiva ou negativa. Reveste-se de forma positiva quando o turbador, sem desapossar o possuidor, pratica atos de ocupação do imóvel, no todo ou em parte. Tem a forma negativa quando os atos turbativos impedem o possuidor livremente de exercitar a sua posse. Por esbulho entende-se ato violento, em virtude do qual uma pessoa é despojada contra sua vontade, daquilo que lhe pertence ou está em sua posse. É uma usurpação. Se a lei assegura ao usurpado ou esbulhado o direito imediato de defender sua posse, mediante ação de reintegração - que tem por objetivo integrá-lo na posse de que foi violentamente privado - esses procedimentos judiciais, no entanto, são extremamente morosos e até por isto empurram litígios para uma ação mais violenta.

A rápida expropriação dessa fração social que não dispõe, via de regra, de documentos legalizadores da propriedade e se funda num direito costumeiro de ocupação, consiste na "compra" de partes da chapada de alguns situantes, que a utilizam complementarmente à grota. Ao se valerem desse expediente, privatizam, pela transação efetuada, uma terra que é considerada devoluta, segundo a legislação brasileira, e comum, do ponto de vista dos que habitam a grota. Esse tipo de invasão implica um tipo específico de expropriação e da concepção de mercadoria que a acompanha: a transformação da terra de chapada, que é originalmente devoluta, em terra negociável, é procedimento que tem várias consequências para os que habitavam as grotas. A venda ou invasão de sua parte de terra costumeira e a chapada no comum abre caminho para a presença física e social do empreendimento agrícola, 
reflorestador, do uso comercial da água, precedidos muitas vezes pela devastação ambiental. Multiplica-se, então, o número de carvoarias nas baixadas mais próximas.

O confronto de formas distintas de apropriação da terra e a decisão sobre qual delas irá prevalecer estão no âmago das invasões efetuadas em áreas de posse. O confronto entre os homens é sempre uma forma inevitável, por meio da qual a agitação das diferentes práticas e verdades jurídicas se dá e sobre qual delas deverá prevalecer. A iniciativa da invasão funciona como verdadeiro decreto de extinção de um modo de vida. $O$ situante não tem mais que duas opções de sobrevivência: ou se subordina, para então ser alvo perpetrado pelo agronegócio ou resiste na terra, situação esta que pela extrema violência só pode ser praticada por uma grande coletividade de atingidos.

A frequência com que os processos se referem à decisão de oficiais de justiça de serem tolerantes para com o invasor, esperando que este compreenda que deve abandonar a área onde mora e planta e, finalmente, sua decisão de invadir a mesma em nome da lei, valendo-se de requisição de força policial, evidencia diferentes faces de litígio: o território da caridade, o território do patrão-cliente e o território das rupturas violentas. A alegação para o último tipo de procedimento é de que o situante seria ele próprio, o iniciante da violência física: está armado e poderá resistir.

A invasão ganha, então, seu último contorno. Se a morada e os pertences devem ser abandonados, se a "desapropriação" feita pelos oficiais de justiça e em certos casos pela presença da polícia está para se consumar, não resta ao situante senão tirar da terra tudo o que plantou, consubstanciando em espécie a indenização pela perda de suas condições de vida. Tornam-se muitas vezes o trabalho que não pode ser aproveitado, que tem de ser destruído. Isto se não for cogitada pela empresa a destruição da roça pelo incêndio. $O$ lavrador que plantava sempre e muito, planta cada vez mais, enche a terra de benfeitorias enquanto houver água vertente disponível porque esta acabará de uma hora para outra. Porque, se nem esta nem o trabalho são reconhecidos como livres e próprios, é a benfeitoria que encarna pela lei da natureza o que nasce, cresce, dá frutos, pelo trabalho humano. É um procedimento que reforça e magnifica a antiga solidariedade do ajutório, ou seja, da ajuda mútua também conhecida pelo nome de mutirão em outras regiões, evidenciando que é no repertório dos costumes que um grupo social procura salvar seu sentido e sua continuidade. Por outro lado, ele caracteriza de modo irretorquível a natureza coletiva dos conflitos. Ao olhar desprevenido, a reação do situante pode parecer uma luta individual e alienante; ao olhar atento, trata-se de atos e 
vontades, providos de um poder altamente mobilizador dos envolvidos e de toda a comunidade a qual pertence.

No Vale do Jequitinhonha a força destas práticas cristalizou-se num conhecido caso de resistência na terra no comum, no município de Turmalina, e sua razão social exemplifica hoje esforços feitos por uma ação coletiva com o objetivo de evitar o fim de várias terras no município de Turmalina. Infelizmente, a morte do principal líder camponês da região, Vicente Nica, em 1993, debilitou o discurso e a prática favoráveis à resistência na terra camponesa²

A observação das mudanças da posse da terra acima descritas aponta em primeiro lugar para a finalização das mediações judiciais para a solução de conflitos. Houve perdas substanciais nesse sentido, enquanto nos anos 1990 havia um grande número de ações judiciais em curso para sua resolução. Ao mesmo tempo mudanças climáticas e dramáticas ocorreram. No nordeste de Minas Gerais registraram-se secas que atingem o abastecimento de águas das cidades do Jequitinhonha. Um dos fatores dessas secas é a diminuição da vazão dos rios pelo desmatamento e pelo desaparecimento das águas vertentes, que eram fatores de alimentação dos rios. A diminuição da vazão dos cursos de águas aponta para desvios ocorridos, bem como a extinção de nascentes. Nesses territórios uma nova luta pela posse da terra e da água começa a se desenhar.

Bibliografia

BOURDIEU, Pierre. Le désenchantement du monde: travail et travaillers en Algérie. Argel: Centre de Sociologie Européenne, 1966.

GLUCKMAN, Max. The Ideas in Barotse Jurisprudence. New Haven/London: Yale University Press, 1965.

MOURA, Margarida Maria. Os deserdados da terra. $2^{\mathrm{a}}$ ed. Curitiba: Brazil Publishing, 2018. MOURA, Margarida Maria; NICA, Vicente - Vicente fala: uma mão na terra outra no coração (a luta camponesa no Vale do Jequitinhonha). Rio de Janeiro/São Paulo: Instituto Apoio

\footnotetext{
2 Vicente Fala: Uma Mão na Terra Outra no Coração (a luta camponesa no Vale do Jequitinhonha). Entrevista de Vicente Gonçalves Afonso, o Vicente Nica a Márcia Angelina Alves, Margarida Maria Moura, Sônia Lacerda, Maria Teresa Araújo, Paula Elaine Covo e Eduardo Graziano. Rio de Janeiro/São Paulo, Instituto Apoio Jurídico Popular/ FASE - Federação de Órgãos para Assistência Social e Educacional/ Departamento de Antropologia da FFLCH-USP, 1993.
} 
Jurídico Popular/ FASE - Federação de Órgãos para Assistência Social e Educacional/ Departamento de Antropologia da FFLCH-USP, 1993.

WOLF, Eric. The social Anthropology of complex societies. London: ASA Monographs, Tavistock Publications, 1966. 